\title{
Induction of water stress tolerance of mustard plants using Trichoderma as biological seed treatment
}

\author{
K. K. Sharma ${ }^{1}$ and U. S. Singh ${ }^{2}$ \\ ${ }^{1}$ Vivekanand Parvatiya Krishi Anusandhan Sansthan, Almora-263601, (Uttarakhand), INDIA \\ ${ }^{2}$ IRRI, 9th Floor, Aggarwal Corporate Tower, Plot No. - 23, Rajendra Place, New Delhi - 110 008, INDIA \\ *Corresponding author. E-mail: abhay23p@yahoo.com
}

Received: March 31, 2014 :Revised received: August 01, 2014: Accepted: October 05, 2014

\begin{abstract}
Water scarcity is one of the main consequences of changing climate which adversely affects the plant growth and productivity. Enhanced root development results in increased surface area of active absorption for water and nutrient uptake which helps in tolerating abiotic stresses including drought in plants. Trichoderma is well known for its biocontrol and growth promontory effect in plants in addition to alleviate abiotic stress. In our study, thirty isolates of Trichoderma were grown on sterilized cow dung at different moisture content ranges from 5 to 30 percent to investigate their ability to grow and multiply under water stress condition. Mustard plants were grown under glass house condition by treating seeds with selected isolates of Trichoderma subjected to water stress subsequently. All isolates of Trichoderma grew upto $20 \%$ moisture whereas only eleven isolates exhibited growth at $10 \%$ moisture. Isolate PB23 was only isolate which was able to grow and resulted in $1.0 \times 10^{9} \mathrm{cfu} / \mathrm{g}$ air dried cow dung even at $5 \%$ moisture content and induced the tolerance of mustard plants under water stress conditions when applied as seed treatment before sowing.
\end{abstract}

Keywords: Mycorrhiza, PGPF, Tensiometer, Trichoderma, Water stress

\section{INTRODUCTION}

Drought stress is one of the key factor limiting plant growth and productivity in many areas (Gusain et al., 2014). Root size and architecture are the factors which determine yield performance, particularly under conditions of limited water availability (Price et al., 2000). The arbuscular mycorrhizal (AM) and vesicular arbuscular mycorrhizal (VAM) fungi are ubiquitous component of most agro-ecosystems, symbiotically associated with roots of various plants forming a network of fungal mycelium with roots of host plant, increase active absorptive surface area of roots results in enhanced nutrient uptake and drought stress tolerance (Farahani et al., 2008, Naher et al., 2013 and Smith and Read, 2008) in a variety of crops. Among several strategies including mycorrhizal fungi use to improve crop yield under stress conditions, the use of bio-agents such as Trichoderma is an effective and easily adaptive strategy (Bailey et al., 2006). For the several reasons like enhancement of overall plant growth including increased nutrient absorption and stress resistance (Hoyos-Carvajal et al., 2009), Trichoderma species are also recognized as plant growth promoting fungi (PGPF) (Hyakumachi and Kubota, 2004 and Doni et al., 2013). Zaidi and Singh (2004) and Shukla et al. (2012) studied the effect of different moisture levels on growth and multiplication of Trichoderma harzianum using cow dung as substrate.
Trichoderma spp. can improve the early stage of plant development through the enhancement of root growth and root length which is the primary direct effect of Trichoderma colonization regardless of water status, which caused delay in the drought responses (Shukla et al., 2012). Interestingly, some genes of Trichoderma species have also been reported which can be used to give resistance to the abiotic stresses including drought (Mastouri et al., 2010). A few recent reports demonstrated that PGPF, Trichoderma spp. alleviate abiotic stresses and indicates that they may confer tolerance to drought stress at least in part through promotion of deeper root penetration into the soil profile (Daniel et al., 2011).

In the present investigation thirty isolates of Trichoderma were subjected to grow on sterilized and air dried cow dung at different moisture levels. Subsequently selected isolates were also tested for their ability to induce the water stress tolerance in mustard plants when used as seed treatment prior to sowing. The reason behind evaluation of drought tolerance in the current strains of plant growth promoting fungi (PGPF), Trichoderma was that the stress tolerant strains can be efficiently deployed in extreme environments where they can show better rhizosphere competence and saprophytic competitive ability.

\section{MATERIALS AND METHODS}

Experimental materials, Trichoderma strains were 
isolated from rhizospheric soils of different crops and locations of Uttarakhand (Table 1) and mustard seeds (var. Varuna) were obtained from oil seed pathology lab G.B.P.U.A. \& T. Pantnagar respectively. Cow dung was used to study the growth of isolates at moisture stress conditions. The clots were removed and $50 \mathrm{~g}$ cow dung was filled in $250 \mathrm{ml}$ Erlenmeyer flasks. Different amount of water was added to maintain 30 , $25,20,15,10$ and 5 per cent moisture (based on air dried cow dung). The flasks were autoclaved at $15 \mathrm{lbs}$ psi. for 30 minutes and three flasks were maintained for each moisture level. The flasks were inoculated with 2 $\mathrm{ml}$ spore suspension of individual Trichoderma isolate. The inoculated flasks were incubated at $26 \pm 2{ }^{0} \mathrm{C}$ for 14 days. Flasks were weighed regularly and loss of moisture was replenished by adding sterilized water and $1 \mathrm{~g}$ of air dried samples were estimated for Trichoderma population by serial dilution method using TSM medium (Zaidi and Singh, 2004).

On the basis of growth performance at different moisture regimes on cow dung selected isolates were also evaluated for their ability to enhance water stress tolerance of mustard plants moisture stress conditions. Plastic pots ( $2.5 \mathrm{~kg}$ capacity) were filled with $2.0 \mathrm{~kg}$ autoclaved soil and saturated with water holding

Table 1. Isolates of Trichoderma with source of soil samples. calibrated tensiometer. Seeds were treated with powdered formulations of selected isolates of Trichoderma except for control. Treated brassica seeds were sown at 60 percent moisture content in pots holding a tensiometer. Three replications for each treatment including control and finally with five plants per pot were maintained. Moisture was maintained with adding known amount of water until plants attained the age of three weeks and at this point stress was given by stop watering. From the next day observations were taken daily on the basis of readings in tensiometer from initiation of wilting in control till the complete wilting (Shukla et al., 2012).

\section{RESULTS}

Growth of Trichoderma isolates at different moisture levels: All Trichoderma isolates were evaluated for their growth response at six moisture levels $(30,25$, $20,15,10$ and $5 \%$ ) and results are presented in table 2 . PB23 resulted in maximum population (cfu/g air dried substrate) followed by PB 18 at 30 and $25 \%$ moisture while minimum population was recorded for PB11. Growth of the isolates PB 2 and 9; PB 16, 27 and 29, PB 1, 8 and 26; PB 3, 7, 15 and 17; PB 4, 5, 6, 25, 28 and 30; PB 29 and 22; PB 14 and 21; PB 10, 12, 13

\begin{tabular}{|c|c|c|c|c|}
\hline S. No. & Sample code & Crop & Location & Isolate code \\
\hline 1 & R1KG & Rice & Kathgodam-Haldwani & PB1 \\
\hline 2 & R3H & Rice & Halduchaur-Haldwani & PB2 \\
\hline 3 & $\mathrm{R} 2 \mathrm{LCb}$ & Rice & Lamachaur-Haldwani & PB3 \\
\hline 4 & R1Da & Rice & Kherna-Almora & PB4 \\
\hline 5 & $\mathrm{R} 1 \mathrm{Db}$ & Rice & Kherna-Almora & PB5 \\
\hline 6 & $\mathrm{R} 2 \mathrm{Da}$ & Rice & Kherna-Almora & PB6 \\
\hline 7 & $\mathrm{R} 2 \mathrm{Db}$ & Rice & Kherna-Almora & PB7 \\
\hline 8 & SPC1 & Rice & SPC-Pantnagar & PB8 \\
\hline 9 & SPC2 & Rice & SPC-Pantnagar & PB9 \\
\hline 10 & $1 \mathrm{a}$ & Rice & Rudrapur-U.S. Nagar & PB10 \\
\hline 11 & $1 \mathrm{ab}$ & Rice & Rudrapur-U.S. Nagar & PB11 \\
\hline 12 & $1 \mathrm{bc}$ & Rice & Rudrapur-U.S. Nagar & PB12 \\
\hline 13 & 3 & Rice & Rudrapur-U.S. Nagar & PB13 \\
\hline 14 & 5 & Rice & Rudrapur-U.S. Nagar & PB14 \\
\hline 15 & $\mathrm{AM}$ & Apple & Mukteshwar-Almora & PB 15 \\
\hline 16 & $\mathrm{BM}$ & Broccoli & Mukteshwar-Almora & PB 16 \\
\hline 17 & PM1 & Pea & Mukteshwar-Almora & PB17 \\
\hline 18 & PM2 & Pea & Mukteshwar-Almora & PB 18 \\
\hline 19 & SM & Strawberry & Mukteshwar-Almora & PB19 \\
\hline 20 & WM & Walnut & Mukteshwar-Almora & PB20 \\
\hline 21 & RP1 & Rice & Premnagar-Dehradun & PB21 \\
\hline 22 & TR1 & Mustard & Premnagar-Dehradun & PB22 \\
\hline 23 & $\mathrm{~A}$ & Maize & Dhalwala-Rishikesh & PB23 \\
\hline 24 & $\mathrm{~B}$ & Maize & Bhaniawala-Dehradun & PB24 \\
\hline 25 & $\mathrm{~B} 1$ & Rice & Bhaniawala-Dehradun & PB25 \\
\hline 26 & $\mathrm{C} 1$ & Rice & Mazra-Ranipokhri & PB26 \\
\hline 27 & $\mathrm{D}$ & Maize & Geetanagar Rishikesh & PB27 \\
\hline 28 & D1 & Rice & Raipur-Dehradun & PB28 \\
\hline 29 & $\mathrm{~F} 1$ & Rice & Raiwala-Hardwar & PB29 \\
\hline 30 & G1 & Rice & Nagani, Tehri Garhwal & PB30 \\
\hline
\end{tabular}


Table 2. Trichoderma population (cfu/g) at different moisture regimes.

\begin{tabular}{|c|c|c|c|c|c|c|c|}
\hline \multirow[t]{3}{*}{ Isolate code } & \multicolumn{6}{|c|}{ Trichoderma population (cfu/g air dried cow dung) } & \multirow[t]{3}{*}{ Mean } \\
\hline & \multicolumn{6}{|c|}{ Moisture content (\%) } & \\
\hline & 30 & 25 & 20 & 15 & 10 & 5 & \\
\hline PB1 & $3.7 \times 10^{9}$ & $3.3 \times 10^{9}$ & $2.7 \times 10^{9}$ & $1.7 \times 10^{9}$ & $0.3 \times 10^{9}$ & 0.0 & $2.6 \times 10^{9}$ \\
\hline PB2 & $4.7 \times 10^{9}$ & $4.3 \times 10^{9}$ & $3.7 \times 10^{9}$ & $2.3 \times 10^{9}$ & $0.7 \times 10^{9}$ & 0.0 & $1.8 \times 10^{9}$ \\
\hline PB3 & $3.3 \times 10^{9}$ & $3.0 \times 10^{9}$ & $2.7 \times 10^{9}$ & $1.7 \times 10^{9}$ & 0.0 & 0.0 & $1.2 \times 10^{9}$ \\
\hline PB4 & $2.7 \times 10^{9}$ & $2.3 \times 10^{9}$ & $1.3 \times 10^{9}$ & $0.7 \times 10^{9}$ & 0.0 & 0.0 & $1.3 \times 10^{9}$ \\
\hline PB5 & $2.7 \times 10^{9}$ & $2.3 \times 10^{9}$ & $1.7 \times 10^{9}$ & $1.0 \times 10^{9}$ & 0.0 & 0.0 & $1.1 \times 10^{9}$ \\
\hline PB6 & $2.7 \times 10^{9}$ & $2.0 \times 10^{9}$ & $1.7 \times 10^{9}$ & $0.3 \times 10^{9}$ & 0.0 & 0.0 & $1.7 \times 10^{9}$ \\
\hline PB7 & $3.3 \times 10^{9}$ & $3.3 \times 10^{9}$ & $2.7 \times 10^{9}$ & $0.7 \times 10^{9}$ & 0.0 & 0.0 & $1.9 \times 10^{9}$ \\
\hline PB8 & $3.7 \times 10^{9}$ & $3.3 \times 10^{9}$ & $3.0 \times 10^{9}$ & $1.3 \times 10^{9}$ & $0.3 \times 10^{9}$ & 0.0 & $2.7 \times 10^{9}$ \\
\hline PB9 & $4.7 \times 10^{9}$ & $4.7 \times 10^{9}$ & $3.3 \times 10^{9}$ & $2.3 \times 10^{9}$ & $1.3 \times 10^{9}$ & 0.0 & $1.0 \times 10^{9}$ \\
\hline PB10 & $1.7 \times 10^{9}$ & $1.7 \times 10^{9}$ & $1.7 \times 10^{9}$ & $1.0 \times 10^{9}$ & 0.0 & 0.0 & $0.5 \times 10^{9}$ \\
\hline PB11 & $1.3 \times 10^{9}$ & $1.0 \times 10^{9}$ & $0.3 \times 10^{9}$ & $0.3 \times 10^{9}$ & 0.0 & 0.0 & $0.8 \times 10^{9}$ \\
\hline PB12 & $1.7 \times 10^{9}$ & $1.3 \times 10^{9}$ & $1.0 \times 10^{9}$ & $0.7 \times 10^{9}$ & 0.0 & 0.0 & $0.7 \times 10^{9}$ \\
\hline PB13 & $1.7 \times 10^{9}$ & $1.3 \times 10^{9}$ & $1.0 \times 10^{9}$ & $0.3 \times 10^{9}$ & 0.0 & 0.0 & $0.9 \times 10^{9}$ \\
\hline PB14 & $2.0 \times 10^{9}$ & $1.7 \times 10^{9}$ & $1.3 \times 10^{9}$ & $0.7 \times 10^{9}$ & 0.0 & 0.0 & $2.0 \times 10^{9}$ \\
\hline PB15 & $3.3 \times 10^{9}$ & $3.0 \times 10^{9}$ & $2.7 \times 10^{9}$ & $2.3 \times 10^{9}$ & $0.7 \times 10^{9}$ & 0.0 & $2.4 \times 10^{9}$ \\
\hline PB16 & $4.3 \times 10^{9}$ & $3.7 \times 10^{9}$ & $3.0 \times 10^{9}$ & $2.3 \times 10^{9}$ & $1.0 \times 10^{9}$ & 0.0 & $1.9 \times 10^{9}$ \\
\hline PB17 & $3.3 \times 10^{9}$ & $3.3 \times 10^{9}$ & $2.7 \times 10^{9}$ & $2.0 \times 10^{9}$ & $0.3 \times 10^{9}$ & 0.0 & $2.3 \times 10^{9}$ \\
\hline PB18 & $5.0 \times 10^{9}$ & $4.3 \times 10^{9}$ & $2.7 \times 10^{9}$ & $1.7 \times 10^{9}$ & $0.3 \times 10^{9}$ & 0.0 & $1.2 \times 10^{9}$ \\
\hline PB19 & $2.3 \times 10^{9}$ & $2.0 \times 10^{9}$ & $1.7 \times 10^{9}$ & $1.3 \times 10^{9}$ & 0.0 & 0.0 & $0.6 \times 10^{9}$ \\
\hline PB20 & $1.7 \times 10^{9}$ & $1.3 \times 10^{9}$ & $0.3 \times 10^{9}$ & $0.0 \times 10^{9}$ & 0.0 & 0.0 & $1.0 \times 10^{9}$ \\
\hline PB21 & $2.0 \times 10^{9}$ & $1.7 \times 10^{9}$ & $1.3 \times 10^{9}$ & $1.0 \times 10^{9}$ & 0.0 & 0.0 & $1.0 \times 10^{9}$ \\
\hline PB22 & $2.3 \times 10^{9}$ & $2.0 \times 10^{9}$ & $1.3 \times 10^{9}$ & $0.3 \times 10^{9}$ & 0.0 & 0.0 & $3.7 \times 10^{9}$ \\
\hline PB23 & $6.0 \times 10^{9}$ & $5.3 \times 10^{9}$ & $4.0 \times 10^{9}$ & $3.3 \times 10^{9}$ & $2.3 \times 10^{9}$ & $1.0 \times 10^{9}$ & $2.3 \times 10^{9}$ \\
\hline PB24 & $4.0 \times 10^{9}$ & $3.7 \times 10^{9}$ & $3.0 \times 10^{9}$ & $2.3 \times 10^{9}$ & $1.0 \times 10^{9}$ & 0.0 & $1.3 \times 10^{9}$ \\
\hline PB25 & $2.7 \times 10^{9}$ & $2.3 \times 10^{9}$ & $1.7 \times 10^{9}$ & $1.0 \times 10^{9}$ & 0.0 & 0.0 & $1.8 \times 10^{9}$ \\
\hline PB26 & $3.7 \times 10^{9}$ & $3.3 \times 10^{9}$ & $2.7 \times 10^{9}$ & $1.3 \times 10^{9}$ & 0.0 & 0.0 & $2.4 \times 10^{9}$ \\
\hline PB27 & $4.3 \times 10^{9}$ & $3.7 \times 10^{9}$ & $3.3 \times 10^{9}$ & $2.3 \times 10^{9}$ & $0.7 \times 10^{9}$ & 0.0 & $1.2 \times 10^{9}$ \\
\hline PB28 & $2.7 \times 10^{9}$ & $2.3 \times 10^{9}$ & $1.7 \times 10^{9}$ & $0.7 \times 10^{9}$ & 0.0 & 0.0 & $1.9 \times 10^{9}$ \\
\hline PB29 & $4.3 \times 10^{9}$ & $3.3 \times 10^{9}$ & $2.7 \times 10^{9}$ & $1.3 \times 10^{9}$ & 0.0 & 0.0 & $1.3 \times 10^{9}$ \\
\hline PB30 & $2.7 \times 10^{9}$ & $2.3 \times 10^{9}$ & $2.0 \times 10^{9}$ & $0.7 \times 10^{9}$ & 0.0 & 0.0 & $1.9 \times 10^{9}$ \\
\hline Mean & $3.1 \times 10^{9}$ & $2.8 \times 10^{9}$ & $2.2 \times 10^{9}$ & $1.3 \times 10^{9}$ & $0.3 \times 10^{9}$ & 0.0 & $1.6 \times 10^{9}$ \\
\hline sem $1=0.05$ & & & & $\mathrm{n} 2=0.11$ & & $\operatorname{sem} 3=$ & \\
\hline cd1 at $5 \%=0.14$ & & & & $5 \%=0.31$ & & $\mathrm{~cd} 3$ at $5^{c}$ & .77 \\
\hline
\end{tabular}

and 20 were at par at $30 \%$ moisture. Maximum population was obtained for PB23 followed by PB 2 whereas minimum population was recorded for $\mathrm{PB} 11$ and 20 at $20 \%$ moisture. Growth of the isolates PB 9 and 27; PB 1, 3, 7, 15, 17, 18, 26 and 29; PB 8, 16 and 24; PB 5, 6, 10, 19, 25 and 28; PB 4, 14, 21 and 22; PB 12 and 13; PB 11 and 20 were at par at $20 \%$ moisture. The growth of all isolates was drastically reduced at moisture below 20\%. Isolate PB 20 did not produce any population at $15 \%$ moisture. Only 11 isolates exhibited growth at $10 \%$ moisture. Interestingly, isolate PB 23 was only isolate which was able to grow and resulted in $1.0 \times 10^{9} \mathrm{cfu} / \mathrm{g}$ air dried cow dung at $5 \%$ moisture level.
Effect of seed treatment with Trichoderma on water stress tolerance of the mustard plants: On the basis of growth performance on cow dung at different moisture level, five isolates (PB2, 8, 9, 18 and 23) from different growth promoting categories were evaluated for their ability to enhance water stress tolerance of mustard plants when used as seed treatment under glass house condition. Results are summarized in Table 3. No sign of wilting was observed in the plants of any treatment at 15-16 centibar soil suction pressure as compare to check $1^{\text {st }}$ day after water stress (DAWS). Incipient wilting was observed in treatment PB2 and PB18 $2^{\text {nd }}$ day after water stress at 21-23 centibar soil suction pressure which completely wilted 
Table 3. Effect of seed treatment with Trichoderma on water stress tolerance of the mustard plants.

\begin{tabular}{|c|c|c|c|c|c|c|c|c|}
\hline \multirow{2}{*}{\multicolumn{2}{|c|}{ Days }} & \multirow[t]{2}{*}{ Parameters } & \multicolumn{6}{|c|}{ Treatments } \\
\hline & & & PB 2 & PB 8 & PB9 & PB 18 & PB 23 & Control \\
\hline \multirow{2}{*}{\multicolumn{2}{|c|}{1 Day after Water stress }} & Suction(cb) & 15 & 16 & 16 & 15 & 16 & 15 \\
\hline & & Wilting & - & - & - & - & - & + \\
\hline \multirow{2}{*}{\multicolumn{2}{|c|}{2 Days after Water stress }} & Suction(cb) & 21 & 21 & 22 & 21 & 23 & 23 \\
\hline & & Wilting & + & - & - & + & - & ++ \\
\hline \multirow{2}{*}{\multicolumn{2}{|c|}{3 Days after Water stress }} & Suction(cb) & 33 & 34 & 33 & 34 & 35 & 34 \\
\hline & & Wilting & ++ & + & - & ++ & - & ++++ \\
\hline \multirow{2}{*}{\multicolumn{2}{|c|}{4 Days after Water stress }} & Suction (cb) & 43 & 44 & 45 & 43 & 45 & \\
\hline & & Wilting & ++++ & ++ & + & ++++ & + & \\
\hline \multirow{2}{*}{\multicolumn{2}{|c|}{5 Days after Water stress }} & Suction (cb) & & 58 & 56 & & 58 & \\
\hline & & Wilting & & ++++ & ++ & & + & \\
\hline \multirow{2}{*}{\multicolumn{2}{|c|}{6 Days after Water stress }} & Suction (cb) & & & 73 & & 75 & \\
\hline & & Wilting & & & ++++ & & ++++ & \\
\hline \multicolumn{9}{|c|}{$<20 \%$ Wilting } \\
\hline++ & \multicolumn{8}{|c|}{$20-40 \%$ Wilting } \\
\hline+++ & \multicolumn{8}{|c|}{ 41-70\% Wilting } \\
\hline++++ & \multicolumn{8}{|c|}{$70-100 \%$ Wilting } \\
\hline
\end{tabular}

$4^{\text {th }}$ day after water stress at 43 centibar soil suction pressure while the control plants wilted $3^{\text {rd }}$ day after water stress. Plants of treatment PB8 were wilted $5^{\text {th }}$ day after water stress at 58 centibar soil suction pressure. The plants of treatment PB9 and PB23 exhibited incipient wilting $4^{\text {th }}$ and $5^{\text {th }}$ DAWS respectively however plants of both the treatments were wilted $6^{\text {th }}$ day after stress at 73-75 centibar of soil suction pressure and hence both these isolates enhanced the water stress tolerance of mustard plants. Isdolate PB 23 induced maximum tolerance to water stress of mustard plants.

\section{DISCUSSION}

Results revealed that all isolates of Trichoderma multiplied best on $30 \%$ moisture (w/w) with maximum growth $\left(6 \times 10^{9} \mathrm{cfu} / \mathrm{g}\right.$ air dried cow dung). They grew up to $20 \%$ moisture with lowest population of $0.3 \times 10^{9} \mathrm{cfu} / \mathrm{g}$ however, growth was drastically reduced beyond $20 \%$ moisture. At 5\% moisture level there was no growth except one isolates (PB23) indicating its good tolerance to moisture stress. The results are in agreement with the findings of Zaidi and Singh (2004) who studied the effects of moisture content $(10,20,30$, 50 and $70 \% \mathrm{w} / \mathrm{w})$ on the growth and multiplication of T. harzianum PBAT-43 on sterilized or unsterilized cow dung and reported the maximum growth of $T$. harzianum was obtained at $30 \%$ moisture level of air-dried cow dung but decreasing the moisture level below $10 \%$ or increasing to $50 \%$ resulted in the drastic growth reduction of $T$. harzianum. Cow dung-neem cake mixture is already a recommended practice for field multiplication of Trichoderma (KAU, 2002). The results were also supported by Shukla et al. (2012) who reported that out of 43 isolates of $T$. harzianum, only five isolates were able to colonize well on cow dung at low moisture content of 10-20 percent, even though two isolates, Th 56 and Th 75, grew even at 5 percent moisture content.

Out of 30 isolates, only five isolates (PB 2, 8, 9, 18 and 23) of Trichoderma were selected to study drought tolerance in mustard plants on the basis of growth performance on air dried cow dung at different moisture regimes. Glass house experiment revealed the drought tolerance of mustard plants was enhanced by treating the mustard seeds with powdered formulation of Trichoderma. Isolates PB 9 and PB 23 performed well to stand the plants against water stress even $6^{\text {th }}$ day after stress while plants treated with other isolates showed wilting $2^{\text {nd }}$ day after stress. The results are in accordance with Shukla et al. (2012) who investigated the impact of endophytic fungus $T$. harzianum on rice response to drought stress. Among test isolates of Trichoderma, Th 56 induced maximum drought tolerance as treated rice plants recorded only 20-40 percent wilting even at 9 DDS. Trichoderma-colonized rice seedlings were slower to wilt in response to drought. Rawat et al. (2011) observed that Trichoderma strains in plants increases root length, which helps in additional water achievement and in that way increasing the plants ability to resist abiotic stresses (drought, salt etc) and uptake of nutrients. Another recent study has evaluated the behavior of endophytic Trichoderma spp. (T. hamatum strain DIS 219b) that colonize the Theobroma cacao tree caused the significant delay in the onset of many drought induced physiological changes (Bae et al., 2009). Our results are in accordance with Doni et al. (2014) who 
reported that Trichoderma spp. significantly enhanced the water use efficiency of rice plants compared to NPK treatment and control and highest water use efficiency was observed for Trichoderma sp. SL2 treated plants. Drought tolerance in mustard plants using Trichoderma is justified by the fact that enhanced rooting provides increased surface area for absorption and long roots penetrate deeper in soil which can absorb the deep seated water and increase plant stand in water stress conditions. In addition of biocontrol ability of Trichoderma spp., the activity that contributes to the enhancement of root growth and distribution was also considered as a key factor to the prolonged photosynthetic activity and the delayed senescence in rice plants (Mishra and Salokhe, 2011). Ghahfarokhy et al. (2011) reported that colonization of roots with VAM fungi and Trichoderma spp. promoted massive root growth which intern help in improved absorption of nutrients. The physical presence of mycelial mass in rhizosphere is itself would serve as appendages to the normal rhizosphere of plants (Mariola et al., 2007) or development of a plant-fungus relationship similar to that described for mycorrhizal fungi (Barea et al., 2002). The positive role of Trichoderma spp. in ectomycorrhizal sphere has been also elaborated by $\mathrm{Wu}$ et al. (2005) which is an indirect mode for their plant growth promotional activity. Hence findings of our experiments are in agreement with those of the above mentioned authors.

\section{Conclusion}

This study has identified potential drought tolerant strain of Trichoderma (isolate PB 9 and 23) when applied as seed dresser. However, our results demonstrate that seeds treated with Trichoderma resulted in significantly higher survival of drought-stressed mustard plants and in greater biomass production. With or without exposure to drought, colonization by Trichoderma promoted seedling growth, with isolates PB 9 and 23 giving the most consistent effect. This research opens a new way in abiotic stress management in rainfed agro-ecosystems for enhancing crop productivity for the benefit of small and marginal farmers. In this respect, the present study concludes that Trichoderma spp. have the potential to induce drought tolerance and enhance physiological processes and growth. The results of the present study serve as base for the mediation of PGPF in enhancing water stress tolerance in plants and need the evaluation of more strains for growth promotion and productivity of various crops under different environmental stress condition.

\section{REFERENCES}

Bae, H., Sicher, R. C., Kim, M.S., Kim, S. H. and Strem, M. D. (2009). The beneficial endophyte Trichoderma hamatum isolate DIS 219 b promotes growth and delays the onset of the drought response in Theobroma cacao. J. Exp. Bot., 60: 3279-3295.

Bailey, B.A., Bae, H., Strem, M.D., Roberts, D.P., Thomas
S.E., Samuels, G.J., Choi, I.Y. and Holmes, K.A. (2006). Fungal and plant gene expression during the colonization of cacao seedling by endophytic isolates of four Trichoderma species. Planta, 224: 1449-1464.

Barea, J.M., Azcón, R. and Azcón-Aguilar, C. (2002). Mycorrhizosphere interactions to improve plant fitness and soil quality. Ant. Leeuw., 8: 343-35.

Daniel, L.A.E., Praveen Kumar G., Desai, S. and Mir Hassan, A.S.K. (2011). In-vitro Characterization of Trichoderma viride for Abiotic Stress Tolerance and Field Evaluation against Root Rot Disease in Vigna mungo L. J. Biofertil. Biopestici., 2 (3):1-5.

Doni, F., Al-Shorgani, N.K.N., Tibin, E.M.M., Abuelhassan, N.N., Anizan, I., Che-Radziah, C.M.Z. and Wan Mohtar, W.Y. (2013). Microbial involvement in growth of paddy. Curr. Res. J. Biol. Sci., 5(6):285-290.

Doni, F., Isahak, A., Zain, C.R.C.M. and Yusoff, W.M.W. (2014). Physiological and growth response of rice plants (Oryza sativa L.) to Trichoderma spp. inoculants. AMB Express, 4:45.

Farahani, A., Lebaschi, H., Hussein, M., Hussein, S.A., Reza, V.A. and Jahanfar, D. (2008). Effects of arbuscular mycorrhizal fungi, different levels of phosphorus and drought stress on water use efficiency, relative water content and proline accumulation rate of Coriander (Coriandrum sativum L.). Journal of Medicinal Plants Research, 2(6): 125-131.

Ghahfarokhy, M.R., Goltapeh, E.M., Purjam, E., Pakdaman, B. S., Modarres Sanavy, S.A.M. and Varma, A. (2011). Potential of mycorrhiza-like fungi and Trichoderma species in biocontrol of Take-all Disease of wheat under greenhouse condition. Journal of Agricultural Technology, 7(1): 185-195.

Gusain, Y.S., Singh, U.S. and Sharma, A.K. (2014). Enhance activity of stress related enzymes in rice (Oryza sativa L.) induced by plant growth promoting fungi under drought stress. Afr. J. Agric. Res., 9 (19): 1430-1434.

Hoyos-Carvajal, L., Orduz, S. and Bissett, J. (2009). Growth stimulation in bean (Phaseolus vulgaris L.) by Trichoderma. Biological Control, 51.409416

Hyakumachi, M. and Kubota, M. (2004). Fungi as plant growth promoter and disease suppressor. In: Fungal Biotechnology in Agricultural, Food, and Environmental Applications (ed. K.A. Dilip). New York Basel, pp: 101-110.

KAU (2002). Package of practices recommendations: crops. Twelfth Edition. Directorate of Extension, Kerala Agricultural University, Thrissur, 278p.

Mariola, R.C., Rodríguez, O.G., Benítez, T., Sonia S., Rey, M., Llobell, A. and Jarana1, J.D. (2007). Microscopic and transcriptome analyses of early colonization of tomato roots by $T$. harzianum. International Microbiology, 10: 19-27.

Mastouri, F., Björkman, T. and Harman, G.E. (2010). Seed treatment with Trichoderma harzianum alleviates biotic, abiotic and physiological stresses in germinating seeds and seedlings. Phytopathology, 100(11): 1213-1221.

Mishra, A. and Salokhe, V. M. (2011). Rice growth and physiological responses to SRI water management and implications for crop productivity. Paddy Water Environ., 9:41-52.

Naher, U. A., R. Othman and Panhwar, Q.A. (2013). Beneficial effects of mycorrhizal association for crop production in the tropics - a review. Int. J. Agric. Biol., 15: 1021-1028. 
Price, A.H., Steele, K.A., Moore, B.J., Barraclough, P.B. and Clark, L.J. (2000). A combined RFLP and AFLP linkage map of upland rice (Oryza sativa L.) used to identify QTLs for root-penetration ability. Theoretical and Applied Genetics, 100: 49-56.

Rawat. L., Singh, Y., Shukla, N. and Kumar, J. (2011). Alleviation of the adverse effects of salinity stress in wheat (Triticum aestivum L.) by seed biopriming with salinity tolerant isolates of Trichoderma harzianum. Plant Soil, 347(1): 387-400.

Shukla, N., Awasthi, R.P., Rawat, L. and Kumar, J. (2012). Biochemical and physiological responses of rice (Oryza sativa L.) as influenced by Trichoderma harzianum under drought stress. Plant Physiol Biochem., 54:78-88.

Smith, S. E. and Read, D. J. (2008). Mycorrhizal symbiosis, 3rd edn. Academic, London.

Wu, T., Kabir, Z. and Koide, R.T. (2005). A possible role for saprotrophic microfungi in the $\mathrm{N}$ nutrition of ectomycorrhyzal Pinus resinosa, Soil Biol. Biochem., 37: 965-975

Zaidi, N.W. and Singh, U.S. (2004). Use of farmyard manure for mass multiplication and delivery of biocontrol agents, Trichoderma harzianum and Pseudomonas fluorescens. Asian Agri-History, 52: 165-172. 